\title{
Romantic Relationship Patterns From Adolescence to Emerging Adulthood: Associations With Family and Peer Experiences in Early Adolescence
}

\author{
Stéphanie Boisvert ${ }^{1} \&$ François Poulin ${ }^{1}$ \\ ${ }^{1}$ Department of psychology, Université du Québec à Montréal
}

This is a post-peer-review, pre-copyedit version of an article published in Journal of Youth and Adolescence. The final authenticated version is available online at:

https://doi-org/10.1007/s10964-016-0435-0

\section{For citation:}

Boisvert, S., \& Poulin, F. (2016). Romantic relationship patterns from adolescence to emerging adulthood: Associations with family and peer experiences in early adolescence. Journal of Youth and Adolescence, 45(5), 945-958. https://doi-org/10.1007/s10964-016-0435-0

Conflict of Interest: All authors declare that they have no conflicts of interest.

Stéphanie Boisvert, BSc, corresponding author Département de psychologie Université du Québec à Montréal, Case postale 8888, Succursale Centre-Ville Montréal (Québec), Canada H3C 3P8.

E-mail: boisvert.stephanie.3@courrier.uqam.ca 


\begin{abstract}
The present study identifies and describes romantic relationship patterns from adolescence to adulthood and examines their associations with family and peer experiences in early adolescence. In a 13-year longitudinal study, 281 youth (58\% girls) identified all their romantic partners each year from the ages of 16 to 24 . Dimensions of family relationships (family cohesion, parent-child conflict) and peer relationships (peer likeability, social withdrawal, close friendships, other-sex friendships) were assessed at age 12. Latent class analyses brought out five distinct romantic relationship patterns and significant associations were found with family and peer relationships in early adolescence. These five romantic relationship patterns appeared to follow a continuum of romantic involvement, with romantic relationship patterns situated a both ends of this continuum (later involvement pattern and intense involvement pattern) being associated with more interpersonal experiences in early adolescence.
\end{abstract}

Key Words : Longitudinal study; Adolescence; Emerging adulthood; Romantic relationships; Social relationships 


\section{Introduction}

Romantic relationships emerge during adolescence and become increasingly important in subsequent years (Carver, Joyner, \& Udry, 2003). These relationships are often short-lived and allow adolescents to explore different facets of the romantic experience (Brown, 1999). Such exploration carries on into emerging adulthood, a period characterized by a great diversity of life-course trajectories (Arnett, 2000). These different life-course trajectories could have repercussions on individuals' romantic relationship progression. A variety of romantic relationship patterns might thus be observed (Shulman \& Connolly, 2013).

While several studies have examined the development of romantic relationships from adolescence to adulthood (e.g., Cui, Ueno, Fincham, Donnellan, \& Wickrama, 2012), few have considered the possible existence of diverse romantic relationship patterns (an exception being Rauer, Pettit, Lansford, Bates, \& Dodge, 2013). Moreover, in accordance with the social development perspective (Bryant \& Conger, 2002; Sullivan, 1953), it is possible that different romantic relationship patterns show associations with some of the youth's earlier interpersonal experiences in the family and peer group contexts. The current study aimed to identify romantic relationship patterns based on data collected yearly from ages 16 to 24 and to examine associations with aspects of family and peer relationships assessed in early adolescence.

\section{Romantic Relationship Patterns}

Two recent longitudinal studies covering the period of adolescence identified romantic relationship patterns using person-centred analyses. Orpinas and colleagues (2013) surveyed 620 youth regarding their dating activities from ages 12 to 18 . A group-based semiparametric procedure revealed four trajectories (low dating, increasing dating, high middle school dating, and frequent dating). Connolly and colleagues (2013) surveyed 698 youth regarding a variety of 
romantic behaviours from ages 11 to 18 . They examined the sequence in which these behaviours emerged and found three trajectory groups (on-time, early-starters and late-bloomers). These two studies suggest that, in addition to a pattern in which romantic activities emerge toward midadolescence, there also appear to be at least two other romantic relationship patterns, characterized by early or late entry into romantic relationships.

Given that adolescents' exploration in romantic relationships extends to emerging adulthood (Shulman \& Connolly, 2013), one might also expect to find a variety of romantic relationship patterns during this period. In addition to the degree of involvement in romantic relationships (i.e. being involved in romantic relationships or not being involved, and if yes, from what age), the identification of these patterns should also take into account the length of these relationships (i.e. keeping the same partner for a long time versus frequently changing partners). Considering these two dimensions simultaneously should result in a richer portrait of romantic relationship patterns. For instance, these two dimensions vary from one individual to another, showing continuity with the quality of interpersonal skills for some individuals (Cui, Fincham, $\&$ Pasley, 2008), while being associated with risk indicators for others (e.g., Cui, Ueno, Fincham, Donnellan, \& Wickrama, 2012).

Rauer and colleagues (2013) identified distinct romantic relationship patterns using the two dimensions described above. Every year between ages 18 and 25, 511 American emerging adults were asked whether they were in a couple relationship and if yes, the name of their romantic partner. It was thus possible to calculate the number of years these young people had been in a romantic relationship and the number of different romantic partners they had had during this period. A cluster analysis was applied to these two variables and brought out five different romantic relationship patterns. Two of these patterns were characterized by steady 
involvement and the tendency to keep the same partner (steady involvement and long-term committed). Another pattern was characterized by alternating periods of involvement and noninvolvement (sporadic involvement). A fourth pattern was characterized by later entry into romantic relationships (later involvement). The fifth and last pattern was characterized by almost continuous involvement, but with frequent partner changes (frequent involvement).

Rauer et al.'s (2013) results illustrated the existence of different romantic relationship patterns during emerging adulthood. This longitudinal investigation of romantic relationship patterns should be further pursued for at least four reasons. First, it is possible that a methodological constraint slightly confounded the results reported by Rauer et al. (2013). The participants in their study were asked to name the partner with whom they were currently in relationship at the time of data collection each year. However, it is possible that the participants had been in relationships, perhaps lasting several months, between the waves of data collection and that these partners were not named. By failing to include them, the total number of different partners was undoubtedly under-estimated. Second, it is advisable to include the period of adolescence in the study of romantic relationship patterns because the heterogeneity in these patterns appears to emerge during this period (e.g., Orpinas et al., 2013). Including the period of adolescence would thus provide a more complete picture of the development of different romantic relationship patterns. Third, it would be advantageous to examine romantic relationship patterns in other cultures or countries where the commitment behaviours of young couples may vary. For example, in 2011, in Quebec (Canada, where the current study took place), 2.9\% of young people aged 20 to 24 and $13.1 \%$ of young people aged 25 to 29 were married (Institut de la statistique du Québec (ISQ), 2012), compared to rates of 9.3\% and 36.7\%, respectively, in the US during the same period (United States Census Bureau (USCB), 2012). Moreover, in 2013, on 
average, women in Quebec had their first child at age 28.7 (ISQ, 2014) compared to age 26 for American women (Martin, Hamilton, Osterman, Curtin, \& Mathews, 2015). Fourth, the social development perspective (e.g., Bryant \& Conger, 2002; Sullivan, 1953) suggests that romantic relationship patterns may be associated with dimensions of interpersonal experiences in the family and the peer group during early adolescence. This latter point will be discussed in further detail below.

\section{Interpersonal Experiences in the Family and Peer Group during Early Adolescence}

In order to clarify the contribution of family and peer group experiences to the development of romantic relationship patterns, it is preferable to measure these experiences before (but close to) the emergence of romantic relationships. Indeed, once romantic relationships are established during adolescence and emerging adulthood, they are likely to impact family and peer experiences in turn (Furman \& Shaffer, 2003). Given that the first signs of romantic interest among youth are generally observed around the age of 13 (Carver et al., 2003), we directed our attention to aspects of family and peer relationships that are salient in early adolescence (age 12) and could potentially be related to later romantic relationship patterns.

As for experiences within the family, Bryant and Conger (2002) suggest that family interactions in early adolescence could either promote or inhibit development of the interpersonal skills needed to negotiate successful romantic relationships in adulthood. Two aspects appear important to consider in early adolescence, namely, the family as a system and the parent-child relationship. A family system that functions well is characterized, in particular, by a high level of cohesion (Olson, 2000). Youth from families in which there is little cohesion are disengaged from their families and do not find support within them (de Graaf, van de Schoot, Woertman, Hawk, \& Meeus, 2012). They in turn tend to avoid seeking support in their intimate 
relationships, which could compromise their romantic relationship development. A positive association between family cohesion in early adolescence and the quality of romantic relationships in emerging adulthood has, moreover, been documented (Feldman, Gowen, \& Fisher, 1998; Parade, Supple, \& Helms, 2012). Thus, better family cohesion in early adolescence could promote a certain confidence in establishing intimate relationships during adolescence and early adulthood, which in return could contribute to romantic relationships of a longer duration.

Furthermore, early adolescence is marked by the search for autonomy and an affirmation of independence from parents (Steinberg, 2001). This realignment in the parent-child relationship can be accompanied by a temporary increase in conflict (Laursen \& Collins, 2009). However, overly frequent or intense conflict with parents during this developmental period could, through a learning mechanism, lead to a pattern of conflictual interaction with the romantic partner (eg. Bryant \& Conger, 2002), even up to emerging adulthood (Crockett \& Randall, 2006). Since conflictual romantic relationships are less stable (eg. Shulman, TuvalMashiach, Levran, \& Anbar, 2006), this could lead to frequent changes in partners.

From early adolescence, peer relationships begin to play an increasingly important role in youth' social lives. Four elements prove to be particularly salient during this transition period and likely to impact subsequent involvement in romantic relationships: 1) peer likeability, 2) the tendency for some youth to withdraw socially, 3) an increase in closeness in friendships, and 4) the emergence of mixed-gender friendships.

Peer likeability corresponds to the degree to which youth are liked by other youth (Cillessen \& Marks, 2011) and can be considered to be a reflection of social competence (Rubin, Bukowski, \& Parker, 2006), which can subsequently foster the ability to form and maintain romantic relationships (Houser, Mayeux, \& Cross, 2014). Indeed, young adolescents who are 
less liked by their peers are less involved in romantic relationships (Miller, Lansford, Costanzo, Malone, Golonka, \& Killeya-Jones, 2009).

Moreover, some shy and inhibited youth tend to be more withdrawn from the peer group (Rubin, \& Coplan, 2010) and to remain so during subsequent years (Gazelle \& Ladd, 2003). Individuals who are socially withdrawn during childhood date less during adolescence and engage in couple relationships at a later age (Caspi, Elder, \& Bem, 1988; Kerr, Lambert, \& Bem, 1996).

The need to experience closeness outside the family with a friend of the same gender emerges in early adolescence and increases in subsequent years (Sullivan, 1953). The social development perspective argues that the skills acquired in these friendships and the ability to share intimacy are subsequently extended to romantic relationships (eg. Buhrmester \& Furman, 1987; Seiffge-Krenke, 2003). Thus, early adolescents who manage to meet this need for intimacy by developing the skills and competencies needed to form close friendships are thought to be more likely to have better quality and thus more stable romantic relationships later on.

Lastly, early adolescence is marked by the end of gender segregation (Maccoby, 1998). Peers from the other gender are gradually included in the friendship network (Poulin \& Pedersen, 2007). Youth who develop other-sex friendships at an earlier age are thus at an advantage in terms of developing romantic relationships, in particular because of the opportunities that a more mixed group of friends provides (Connolly, Furman, \& Konarski, 2000) and because some of these friendships may develop into romantic relationships (Kreager et al., 2015). Therefore, having many other-sex friends in early adolescence might set the stage for romantic relationship patterns characterized by relationships with several partners over time.

\section{The Current Study}


The first goal of this study was to identify and describe romantic relationship patterns from adolescence to emerging adulthood. A sample of French Canadian youth was surveyed regarding their romantic relationships every year from ages 16 to 24 . Our intention was to examine romantic relationship patterns at an age when most youth have begun to experience romantic relationships and when these relationships are more focused on quality and intimacy (Brown, 1999). Person-centred analyses based on two variables, i.e. the number of years in a romantic relationship during the period investigated and the number of different partners, were used to identify romantic relationship patterns. It was hypothetized that the patterns observed would be similar to those found by Rauer et al. (2013), although the emergence of a pattern characterized by a significantly high number of romantic partners was anticipated given the measurement effort made in this study to identify all the partners.

The second goal was to examine whether the romantic relationship patterns identified were associated with the youth's interpersonal experiences in the family context (e.g., family cohesion and parent-child conflict) and peer group context (e.g., peer likeability, social withdrawal, closeness in friendships and mixed-gender friendships) in early adolescence. The hypothesis was that family and peer experiences in early adolescence would differentiate the various romantic relationship patterns. Specifically, higher family cohesion and lower parentchild conflict were expected to be associated with romantic relationship patterns characterized by greater stability (e.g., higher number of years with the same partners). Moreover, higher peer likeability, other-sex friendships, close friendships and lower social withdrawal were expected to be associated with romantic relationship patterns characterized by greater stability.

\section{Methodology}

\section{Participants}


This longitudinal study began in 2001 with 390 Grade 6 pupils (mean age $=12.38$ years; 58\% girls). The sample was drawn from a dozen French-language schools in Quebec (Canada). In all, $75 \%$ of the parents contacted agreed to have their child participate in the study. Most of the participants were Canadian-born (90\%), lived with both biological parents $(72 \%)$ and came from middle class families (mean family income $=\$ 45,000$ to $\$ 55,000$ ). Mothers and fathers had the same average number of years of schooling (13.10 and 13.20 years, respectively).

Like any longitudinal study, this study had missing data. Between the ages of 16 and 24, the annual rates of participant retention varied between $77 \%$ and $82 \%$ of the initial sample. Given that one of the key pieces of information on which this study was based was nominal in nature (i.e. the name of the romantic partners), the usual methods of estimating missing data could not be applied. A sub-sample was thus formed based on the following criterion: having participated in at least seven out of nine annual waves of data collection between the ages of 16 and 24. In all, 281 participants $(63 \%$ girls, $p<.05)$ met this criterion. Compared to the group of non-retained participants $(\mathrm{N}=109)$, the retained participants $(\mathrm{N}=281)$ were more likely to have come from intact families $(p<.001)$. At age $24,2.3 \%$ of this sample was married.

\section{Research Design and Procedures}

The participants were followed over a period of 13 years (ages 12 to 24). Antecedents were assessed at age 12 and romantic relationships were assessed yearly between the ages of 16 and 24. At age 12 (Grade 6), questionnaires were completed by the pupils in the classroom under the supervision of undergraduate and Master's student research assistants. In high school (ages 13 to 17), similar procedures were followed. Again, questionnaires were completed in the school setting under the supervision of research assistants. However, as participants were spread throughout more than 30 schools, some assessments had to be conducted individually at the 
participant's home (approximately 10 cases per year) or the questionnaires had to be sent out by mail (approximately 5 per year). After high school, assessments were conducted individually. In most cases, these assessments took place at the participant's home. In some cases, questionnaires were sent out by mail. At ages 23 and 24, the data were collected through a structured telephone interview conducted by trained and supervised undergraduate and Master's student research assistants. Parents provided written consent for their child's participation at each year of the study until the youth were 18 . From ages 18 to 24 , written consent was provided by the participants. From age 16 onwards, the youth received a gift certificate (to a movie theater, music store, or sports store) for their participation at each time point.

\section{Measures}

Romantic relationships. Every year from ages 16 to 22, participants were asked to complete a questionnaire, indicating the first and last names of all the romantic partners (maximum 5) they had had over the previous 12 months. They were then asked to specify, for each of the partners named, how long the relationship had lasted. At ages 23 and 24, this information was collected through a telephone interview. In line with previous studies, only romantic relationships lasting at least one month were retained in the current study (ZimmerGembeck, Siebenbruner, \& Collins, 2001). Several variables were then calculated based on this information.

Number of different romantic partners. The number of different romantic partners named between the ages of 16 and 24 was compiled. The value of this variable ranged from 0 to $\mathrm{X}$.

Number of years in a romantic relationship. This variable was calculated by adding up the number of years in which the participant reported having had at least one romantic partner in the previous year. The value of this variable ranged from 0 to 9 , with a value of 9 indicating that 
the participant reported being in a couple relationship (i.e. named at least one romantic partner) every year between the ages of 16 and 24 . These two variables were used to identify the romantic relationship patterns.

Length of the longest romantic relationship. The length of the longest romantic relationships was determined for each participant by retaining the partner who was named the most often between the ages of 16 and 24 (ranged from 0 to 9).

Age at first romantic relationship. This variable corresponded to the age at which the participant first reported having had a romantic partner (ranged from 16 to 24). A score of 25 was assigned to the participants who reported no romantic relationships between the ages of 16 and $24(n=6)$ to allow them to be included in the analyses.

\section{Antecedents at age 12.}

Family cohesion. The measure of family cohesion assessed the level of emotional bonding between participants and their family members. We used the positive family relations subscale drawn from the questionnaire developed by Metzler, Biglan, Ary and Li (1998). Participants assessed six items on a five-point scale ranging from "not at all true" to "completely true" (sample item: "The members of my family help each other"). A family cohesion score was calculated by averaging the scores for these six items $(\alpha=.88)$.

Parent-child conflict. The measure of parent-child conflict examined the extent to which there was conflict between the participants and their parents, using items derived from the Oregon Youth Study (e.g., Dishion, Ha, \& Véronneau, 2012). The opening question was: In the last week, how many times did the following things happen between you and at least one of your parents? The items were: "We got angry at each other," "We argued at the dinner table," "We had a big argument about a little thing" and "One of us became so angry that he hit 
someone." Each item was scored on a scale ranging from 1 (never) to 6 (more than six times), and the items were averaged. The internal consistency for this scale was adequate $(\alpha=.77)$.

Peer likeability. Sociometric nominations were conducted in each Grade 6 classroom. Over $70 \%$ of the students in each classroom participated in this assessment. Participants were provided with a list of their classmates who were part of the study. They were asked to nominate "Those you would invite to your birthday party or that you like to play with the most" (likedmost nominations; LM) and "Those you would not invite to your birthday party or that you like to play with the least" (liked-least nominations; LL). No restrictions were imposed regarding the gender or number of classmates that could be nominated. The number of LM or LL nominations received from classmates was computed for each participant. These scores were then transformed into $\mathrm{Z}$ scores within each classroom. A social preference score (LM minus LL) was also calculated for each participant, based on Coie and Dodge's (1983) procedure. This social preference score was used as an indicator of the participants' peer likeability.

Social withdrawal. Peer nominations were collected in the Grade 6 classroom using the French version of the items from the Revised Class Play scale (Masten, Morison, \& Pellegrini, 1985). Students whose parents provided permission to participate in the study appeared on an alphabetical roster handed out to the participants. Using this roster, youth were asked to select up to three peers in their classroom who best fit each of the descriptors. A score for each participant was created by summing up the number of nominations received from classmates. These scores were then transformed into $\mathrm{Z}$ scores for each classroom. Social withdrawal was measured by averaging two items ("Prefers playing alone than with others" and "Is always alone"; $r=.89$ ).

Close friendships. We used the close friendship subscale from the Self-Perception Profile for Adolescents (Harter, 1988). This subscale is comprised of five items, scored from 1 to 4, with 
higher scores reflecting a more positive self-image (e.g., "Some youth find it hard to make friends they can really trust BUT Other youth are able to make close friends they can really trust"). For each participant, a close friendship score was calculated by computing the mean of the five items. The internal consistency of this scale was satisfactory $(\alpha=.79)$.

Other-sex friendships. To examine the proportion of other-sex friendships in the friendship network, participants were asked to write down the full name (first and last names) of up to 10 friends. No constraints were imposed regarding the context in which these friendships took place. The friends could be from school, the neighbourhood, an after-school activity, or any other context. In a second step, participants were asked to answer a series of questions for each of the friends named, including the friend's gender and the nature of their relationship. The friends who were designated by the participants as cousins, brothers/sisters or romantic partners were removed from the network and were not considered in the current analyses. These friendships represented fewer than $5 \%$ of the total nominations. The proportion of the friendship network comprised of other-sex friends was computed. The proportion measure was the number of other-sex friends divided by the number of other-sex friends plus the number of same-sex friends (Poulin \& Pedersen, 2007).

\section{Data Analysis Plan}

The analyses were conducted in three steps: 1) identifying the romantic relationship patterns; 2) validating the patterns based on external variables, and 3) examining the interpersonal experiences in early adolescence.

Two variables were used to identify the romantic relationship patterns: (1) the number of different romantic partners between the ages of 16 and 24, and (2) the number of years in a romantic relationship between the ages of 16 and 24 . These two variables were subjected to a 
latent class analysis (PROC LCA, SAS). This person-centred analysis brought out homogeneous sub-groups of participants within a heterogeneous sample (Lanza, Collins, Lemmon, \& Schafer, 2007). As stated by Lanza and her colleagues (2007), latent class analysis has many advantages compared to cluster analysis. First, this type of analysis considers the possibility of error and the probability of belonging to a group. Moreover, the optimal model with regard to the number of classes in the sample is determined by using fit statistics. In our study, the goodness of fit of the optimal model was measured using the Log-Likelihood, Bayesian Information Criterion (BIC), sample-size adjusted BIC (SSA-BIC) and Aikaike Information Criterion (AIC) (Lanza et al., 2007). The entropy was used to determine the degree of uncertainty of the classification (Celeux \& Soromenho, 1996). In order to compare the romantic relationship patterns identified by the latent class analysis, a MANOVA with Tukey's post hoc analysis was performed on the two variables used to identify these patterns. This analysis made it possible to examine where the differences between the patterns lay with regard to the number of different romantic partners between the ages of 16 and 24 and the number of years in a romantic relationship between the ages of 16 and 24.

The romantic relationship patterns were then compared to one another and validated based on external variables other than those that had been used to identify them. These variables were: length of the longest romantic relationship, age at first romantic relationship, and gender. For the comparisons involving the first two variables, a MANOVA with Tukey's post hoc analysis was used. Gender was analyzed using a chi-square analysis.

Lastly, interpersonal experiences in early adolescence were examined using a MANOVA with Tukey's post hoc analysis. This analysis made it possible to determine whether the patterns 
differed from one another with regard to these interpersonal experiences and, if so, where these differences lay.

\section{Results}

\section{Identifying Romantic Relationship Patterns}

Models ranging from two to six classes were tested using latent class analyses. Table 1 presents the results for each model. An examination of the fit statistics for all these models revealed that the Log-Likelihood decreased progressively and then showed a less pronounced decrease between the five- and six-class models. The BIC, SSA-BIC and AIC were lowest for the five-class model compared to all the other solutions. These fit statistics suggested that the five-class model was the model that best fit the data. Furthermore, the entropy of the five-class model was adequate, which confirmed our decision to choose this model. The means and standard deviations of the two grouping variables for each of the five classes are presented in Table 2. A MANOVA comparing the five classes with regard to these two variables revealed significant differences between them (Wilks' $\lambda=.04, F(4,276)=288.03, p<.001)$. These differences concerned the number of different romantic partners $(F(4,276)=219.30, p<.001)$ and the number of years in a romantic relationship $(F(4,276)=468.67, p<.001)$. The post hoc analyses revealed that the number of romantic partners increased significantly from the first to the fifth pattern $(p<.001)$, with the exception of the second and third patterns, which did not differ from one another $(p=.78)$. The post hoc analyses also revealed that the first pattern differed from the other patterns insofar as it showed a low number of years in a romantic relationship $(p<.001)$ and that the second pattern was characterized by a moderate number of years in a romantic relationship $(p<.001)$, whereas the other three patterns were characterized by a high number of years in a romantic relationship and did not differ among themselves. 
The five classes were then compared to one another with regard to the two external variables using a MANOVA and post hoc analysis. Means and standard deviations are reported in Table 3. This analysis revealed that the five romantic relationship patterns differed significantly from one another (Wilks' $\lambda=.36, F(4,276)=45.85, p<.001)$. An examination of the univariate tests indicated that these differences concerned both the length of the longest romantic relationship $(F(4,276)=64.26, p<.001)$ and age at first romantic relationship $(F(4$, $276)=43.90, p<.001)$. The post hoc analyses revealed that the participants in the first pattern were characterized by shorter romantic relationships than those in the other patterns $(p<.001)$, while the participants in the third pattern were characterized by longer romantic relationships $(p$ $<.001)$. Moreover, the participants in the first pattern differed from those in the other four patterns insofar as they were characterized by late entry into romantic relationships $(p<.001)$. Lastly, the romantic relationship patterns also differed with regard to gender $\left(\chi^{2}(4)=26.49, p<\right.$ .001). The participants in the first two patterns were mostly boys whereas those in the other three patterns were mostly girls.

To sum up, the participants in the first pattern $(n=33 ; 11.7 \%)$ were characterized by a low number of romantic partners and a low number of years in a romantic relationship between the ages of 16 and 24. The term "later involvement" was used to refer to this pattern because these youth were also characterized by late entry into romantic relationships. The participants in the second pattern $(n=59 ; 21 \%)$ were characterized by a moderate number of romantic partners and a moderate number of years in a romantic relationship. Since these participants' romantic relationships were spread out over time, this pattern was called "sporadic involvement." The participants in the third pattern $(n=136 ; 48.4 \%)$ were characterized by a moderate number of romantic partners and a high number of years in a romantic relationship. These participants had 
longer-lasting romantic relationships. Thus, this pattern was referred to as "long-term involvement." The participants in the fourth pattern $(n=41 ; 14.6 \%)$ were characterized by a high number of romantic partners and a high number of years in a romantic relationship. This pattern was called "frequent involvement" because of these participants' tendency to frequently change romantic partners while being involved in a romantic relationship in every year of the study. The fifth pattern $(n=12 ; 4.3 \%)$ was made up of participants who presented a very high number of different romantic partners and a high number of years in a romantic relationship. The term "intense involvement" was used to refer to this pattern.

\section{Associations Between Family and Peer Experiences in Early Adolescence and Romantic Relationship Patterns}

Means and standard deviations for each of the antecedents for each romantic relationship pattern are presented in Table 4. A MANOVA including all these variables as a function of the patterns proved to be significant (Wilks' $\lambda=.751, p<.001$ ). An examination of the univariate tests revealed significant effects for all of the variables, except family cohesion $(p=.355)$. A first significant finding concerned parent-child conflict $(p<.01)$. The post hoc analyses revealed that the youth in the intense involvement pattern reported more conflict in their relationship with their parents at age 12 compared to the youth in all the other patterns. With regard to peer relationships, a significant effect was found for peer likeability $(p<.01)$. The post hoc analyses showed that the participants in the long-term and intense involvement patterns were the most well-liked by their classmates at age 12 , whereas the participants in the later involvement pattern were the least well-liked. A third significant finding was noted for social withdrawal $(p<.01)$. The post hoc analyses showed that the participants in the later involvement pattern were the most socially withdrawn, while those in the long-term, frequent and intense involvement patterns were 
the least withdrawn. A significant effect was also found for close friendships $(p<.01)$. The post hoc analyses revealed that the participants in the later involvement pattern perceived less closeness in their friendships at age 12 while the participants in the frequent involvement pattern perceived more closeness in their friendships. Lastly, a significant effect was found for the proportion of other-sex friends in the friendship network $(p<.05)$. The post hoc analyses indicated that the participants in the later involvement pattern had fewer other-sex friends at age 12, while the participants in the frequent and intense involvement patterns had the most other-sex friends.

\section{Discussion}

Recent longitudinal studies using person-centred analyses reported the existence of different romantic relationship patterns from adolescence to young adulthood, including some that were characterized by early or late entry into romantic relationships and others that were characterized by frequent changes in partners (e.g., Connolly et al., 2013; Orpinas et al., 2013; Rauer et al., 2013). The current study followed up on this work and aimed to identify and describe the romantic relationship patterns among a sample of French Canadian youth interviewed from ages 16 to 24 . It also aimed to determine whether these patterns were associated with the youth's interpersonal experiences in the family and peer group at age 12 . The latent class analysis brought out five romantic relationship patterns that differed from one another with regard to external variables as well as several interpersonal experiences. Below, we describe the study's findings in detail and discuss their developmental significance.

\section{Romantic Relationship Patterns}

The five romantic relationship patterns can be described as being along a continuum. At the center was the long-term involvement pattern which included almost half of the participants and was characterized by longer romantic relationships. Two romantic relationship patterns 
including a smaller number of participants were markedly different from this normative pattern. At one end of the spectrum, the later involvement pattern included individuals who were characterized by late entry into romantic relationships. At the other end, the individuals in the intense involvement pattern were characterized by continuous involvement in romantic relationships but with very frequent partner changes. Two other patterns were found between these opposite poles. The participants in the frequent involvement pattern were also characterized by numerous partner changes but to a lesser extent than those in the intense involvement pattern. Lastly, youth in the sporadic involvement pattern were a little more involved in romantic relationships than those in the later involvement pattern but not as involved as those in the other three patterns.

Males and females were not equally represented in each of these romantic relationship patterns. When patterns were characterized by higher levels of romantic involvement (long-term, frequent and intense involvement patterns), females were in the majority. When they were characterised by lower levels of involvement (late and sporadic involvement patterns), males were overrepresented. These results corroborate the literature on gender differences in romantic relationships. Indeed, beginning in adolescence, males are less comfortable than females in navigating themselves in the romantic sphere (Giordano, Manning, Longmore, \& Flanigan, 2012), which could contribute to their lower level of involvement. Additionnaly, females seek more support within their romantic relationship than males (Perrin et al., 2011) as well as investing themselves more in these relationships in order to mainten them (Shulman, Scharf, Livne, \& Barr, 2013). This can explain why females are overrepresented in patterns characterized by more involvement. 
Given the significant similarities between the current study and that by Rauer et al. (2013) (e.g., 10-year longitudinal design with yearly identification of romantic partners, personcentred analyses), a comparison of the results is in order. The findings are similar in several respects. Indeed, both studies brought out five patterns. In most cases, given their striking similarities, we used similar names for these patterns as those proposed by Rauer et al. Moreover, the gender representation in each pattern was similar in both studies. This replication of Rauer et al.'s results in a different cultural context (French Canadian versus American) and covering a slightly different age range (16 to 24 versus 18 to 25 ) thus lends support to the validity of these romantic relationship patterns.

However, some differences in the findings should be highlighted. First, the proportion of individuals in each pattern was somewhat different. For example, in Rauer et al.'s study, the later involvement pattern included the greatest number of individuals $(28.38 \%$ versus $11.74 \%$ in our study) whereas, in our study, the long-term involvement pattern was the most prevalent ( $48.40 \%$ versus $20.74 \%$ for the long-term committed pattern in Rauer et al.'s study). It is possible that these differences can be attributed to the fact that the procedures used to identify the romantic partners were not the same. More specifically, in Rauer et al.'s study, participants were asked to name their current romantic partner, with the result that partners with whom the participant had been involved in a relationship, even for several months, between the yearly waves of data collection, would not have been identified. This procedure might have led to an over-estimation of the real number of individuals in the later involvement pattern. It is plausible that the proportion of individuals in this pattern reported in the current study is closer to reality, since all of the romantic partners with whom the participants were involved in a relationship for at least one month were taken into consideration here. Lastly, this methodological difference might also 
explain the absence in our study of a pattern characterized by a single romantic relationship throughout the entire period under investigation, as was found in Rauer et al.'s study (long-term committed). It is likely that the steady involvement and long-term committed patterns found in Rauer et al.'s study were combined in the long-term involvement pattern found in our study.

Second, while both studies identified a pattern characterized by continuous involvement in a romantic relationship with a frequent change in partners, referred to in both studies as "frequent involvement" ( $16.44 \%$ of Rauer et al.'s sample), ours was the only of the two studies to identify a pattern characterized by very frequent changes in romantic partners (intense involvement). This difference was likely due to the greater precision with which all romantic partners were identified in our study, bringing out a "more extreme" pattern characterized by even more frequent partner changes than those reported by Rauer et al. The small number of participants in this pattern ( $4.27 \%$ of our sample) is not surprising given that it is an atypical trajectory. A similar pattern has also been found in research on sexuality. Specifically, one study showed that at 26 years of age, $4 \%$ of individuals reported having had 20 or more different sexual partners over the course of their lives (Zimmer-Gembeck \& Collins, 2008). It should be noted here that while individuals in atypical trajectories represent only a small part of the population, these individuals often show the highest levels of psychosocial problems (Madsen \& Collins, 2011).

Cultural differences may also have explained some of the divergent findings between the two studies. On average, French Canadians marry and have children at a later age, and stay in school longer (ISQ, 2012; USCB, 2012), which could allow them more time for romantic exploration. This might explain why the long-term involvement pattern was clearly less prevalent in our study. This difference is also reflected in the rate of married couples in the two 
studies; Rauer et al. (2013) reported that $27.6 \%$ of their participants were married at age 25 , compared to $2.3 \%$ in our sample at age 24 .

\section{Interpersonal Experiences in Early Adolescence}

The interpersonal experiences examined in this study helped us to better understand the possible origin of some of these romantic relationship patterns. The most extreme patterns in the spectrum (later involvement and intense involvement) were marked by the greatest differences in interpersonal experiences compared to the other patterns.

The individuals in the later involvement pattern clearly showed problems integrating into the peer group in early adolescence. In fact, at age 12 , they were the most socially withdrawn, were not well liked by their peers, had few other-sex friends and perceived less closeness in their friendships than participants in the other patterns. Two points merit discussion here. First, these results are consistent with previous studies. More specifically, taken one by one, these dimensions of peer relationships in early adolescence have already been shown to be associated with subsequent problems in romantic relationships (Asendorpf \& Wilpers, 1998; Feiring, 1999; Houser, Mayeux, \& Cross, 2014; Seiffge-Krenke, 2003). The current study showed that each of these dimensions was associated with later romantic involvement, even when they were examined simultaneously (i.e. mutivariate analysis). Second, it is possible that social withdrawal is the common thread linking all of these interpersonal experiences. Thus, socially withdrawn youth are particularly prone to being disliked by their peers (Newcomb, Bukowski, \& Pattee, 1993), have lower quality friendships (Rubin, Wojslawowicz, Rose-Krasnor, Booth-LaForce, \& Burgess, 2006) and have greater difficulty forming relationships with other-sex peers, first on a friendship basis and later in romantic relationships (Connolly, Furman, \& Konarski, 2000). Although, in the current study, the participants' interpersonal experiences were all measured 
concomitantly at age 12 , it is also possible to imagine a cascading model, extending from early to late adolescence, in which social withdrawal leads to exclusion from the peer group, which in turn: 1) makes it difficult to form friendships with same-sex peers that are conducive to closeness, and 2) limits the opportunities to form friendships with other-sex peers. Failure in these two relational contexts during adolescence then compromises these individuals' capacity to form romantic relationships at the same age as their peers. Sullivan's interpersonal theory (1953) highlights the developmental importance of friendship. Friendship constitutes a social context that favours several forms of learning which are then extended to romantic relationships. Thus, difficulty forming friendships hinders this learning, which can then lead to difficulty in forming romantic relationships. Although the current findings showed that these individuals tend to form romantic relationships later than their peers, this does not necessarly suggest that the quality of their couple relationships in adulthood differs from that of their peers. More studies are needed to clarify this issue.

The youth in the intense involvement pattern presented a combination of positive experiences in the peer group context and negative experiences in the family context which, at first sight, is intriguing. More specifically, our results showed that these youth were particularly well liked by their classmates in Grade 6, were not socially withdrawn, and had friendship networks that included the highest proportion of other-sex peers. The transition to a mixedgender peer network is a normative phenomenon during adolescence (Poulin \& Pedersen, 2007). However, the individuals in the intense involvement pattern appeared to experience this process earlier than the other youth. These results suggest that these youth were highly involved in their peer group in early adolescence, which may have facilitated greater access to potential romantic partners. 
Moreover, the youth in the intense involvement pattern reported experiencing more frequent conflict with their parents at age 12 than the youth in the other patterns. Two implications emerge from this finding. First, difficulties in the parent-child relationship in early adolescence have been associated with a higher level of involvement in the peer group (Fuligni \& Eccles, 1993). Second, learning to deal with interpersonal conflict in a healthy way is an important challenge during adolescence and a conflictual family environment is likely to compromise this learning. According to the social development perspective, this learned conflictual approach may later be extended to the individual's other significant interpersonal relationships (Bryant \& Conger, 2002). Indeed, one of the main factors that can compromise the quality of romantic relationships during adolescence and lead to the break-up of these relationships is poor conflict resolution between the partners (e.g., Madsen \& Collins, 2011). To sum up, the youth in this pattern were highly involved in their peer group, were well liked by others and easily formed relationships with other-sex peers but had difficulty maintaining these relationships because of an overly conflictual interactional style. However, although our results appear to suggest such a scenario, further studies are needed to confirm this finding.

Compared to the individuals in the intense involvement pattern, those in the frequent involvement pattern reported more closeness in their friendships at age 12 and did not have a conflictual relationship with their parents. The frequent changes in romantic partners reported by the youth in this pattern could simply have been a manifestation of a normal tendency to explore during this developmental period rather than an extension of difficulties experienced in the family or peer group contexts (Arnett, 2000).

The participants in the long-term involvement pattern were only characterized by the fact that they were well liked by their peers at age 12 . These results are consistent with those found 
by Rauer et al. (2013), who reported that the participants in the long-term committed pattern were characterized by positive peer-related experiences. Nevertheless, one would have expected these participants to also be characterized by greater friendship closeness. Indeed, friendship intimacy, which is stronger in close friendships, could be extended to romantic relationships (Seiffge-Krenke, 2000), and is related to the longevity of these relationships (Hill \& Peplau, 1998).

The participants in the sporadic involvement pattern did not stand out from the participants in the other patterns with regard to the interpersonal experiences measured in our study. However, Rauer et al. (2013) found this pattern to be the most strikingly characterized by negative interpersonal experiences. These differences in the findings could be attributed to the methodological differences outlined above. Thus, the participants in Rauer et al.'s sporadic involvement pattern may have had similar characteristics to the participants in the intense involvement or later involvement patterns that emerged in our study. Moreover, this spacing between romantic relationships could simply be a normal form of exploration in romantic relationships (Arnett, 2000), which could explain why these participants were not characterized in any particular way with regard to the interpersonal experiences in early adolescence.

\section{Strengths, Limitations and Future Research}

The methodological strengths of this study include the use of a longitudinal design extending over 13 years (from ages 12 to 24), yearly measures of romantic relationships over 9 years, the detailed identification of all the romantic partners with whom participants were in a relationship (lasting at least one month) and the use of person-centred analyses which brought out the developmental heterogeneity marking this period. 
Some limitations should nevertheless be mentioned. First, participants were asked to name their romantic partners but these partners were not contacted to confirm the existence of a romantic relationship. However, the criterion stipulating that each relationship had to have lasted at least one month and the fact that the participants were asked to specify the full name of their partners may have helped lessen the impact of this limitation. Second, self-report questionnaires were used to assess several interpersonal experiences in early adolescence (4 out of 6 ). This may have resulted in some shared method bias, especially given that the romantic relationships were also self-reported. However, the two interpersonal experiences measured using a different procedure (peer nominations) also brought out the different romantic relationship patterns. Third, the "longest relationship" variable was based on the number of times a partner was named over the course of the study, which limited our ability to distinguish between relationships that lasted only a few months and those that were maintained for over a year. Finally, the current study used a fairly homogeneous sample of youth from a single geographical area. These findings should be replicated with more ethnically and economically diverse samples and with members of the LGBT community.

Research on romantic relationship patterns could be extended in several ways in future studies. First, the current study identified romantic relationship patterns from age 16 onward, an age when the majority of youth have already experienced a romantic relationship (Carver et al., 2003). Starting a study at a younger age might help bring out an early starter pattern. Second, future studies should also carefully track the psychosocial development of individuals over time (e.g., depression, substance use or sexuality) throughout their romantic relationship development to better understand how romance and psychosocial health might evolve together. Finally, although romantic relationships are dyadic in nature, no information on the partners' 
characteristics or the quality of the relationships was taken into account in this study. For example, did the individuals in the different romantic relationship patterns tend to form relationships with partners who presented particular characteristics or were in the same romantic relationship pattern as they were? Do different romantic relationship patterns all lead to the same quality of couple relationships in adulthood? Does the fact of being in a non-normative pattern (e.g., later involvement or intense involvement) from early adolescence to emerging adulthood necessarily result in difficulties that persist into adult romantic relationships? Although the present study provided some important insight into romantic relationship patterns, longitudinal studies with multiple respondents are needed to address these questions.

\section{Conclusion}

Research on developmental romantic relationship patterns is very recent. This study aimed to contribute to this field, bringing many innovative aspects to the literature. First, the romantic relationship patterns were identified more precisely, with all the participants' romantic partners being considered. Moreover, the examination of these romantic relationship patterns began during middle adolescence, a period when romantic relationships begin to be oriented towards intimacy. These elements brought out, for the first time, a romantic relationship pattern characterized by intense involvement in romantic relationships, as well as four other patterns, including one normative pattern that included almost half of the participants. Finally, this study contributes to the literature on romantic relationship patterns by demonstrating that the five patterns identified differed from one another with regard to family and peer interpersonal experiences assessed in early adolescence, especially for the patterns situated at the poles of the romantic involvement continuum. 


\section{References}

Arnett, J. J. (2000). Emerging adulthood: A theory of development from the late teens through the twenties. American Psychologist, 55(5), 469-480. doi: 10.1037/0003-066X.55.5.469

Asendorpf, J. B., \& Wilpers, S. (1998). Personality effects on social relationships. Journal of Personality and Social Psychology, 74(6), 1531-1544. doi: 10.1037/0022-3514.74.6.1531

Brown, B. B. (1999). "You're going out with who?!": Peer group influences on adolescent romantic relationships. In W. Furman, B. B. Brown \& C. Feiring (Eds.), The development of romantic relationships in adolescence (pp. 291-329). NY, US: Cambridge University Press.

Bryant, C. M., \& Conger, R. D. (2002). An intergenerational model of romantic relationship development. In A. L. Vangelisti, H. T. Reis \& M. A. Fitzpatrick (Eds.), Stability and change in relationships: Advances in personal relationships (pp. 57-83). NY, US: Cambridge University Press.

Buhrmester, D., \& Furman, W. (1987). The development of companionship and intimacy. Child Development, 58(4), 1101-1113. doi: http://dx.doi.org/10.2307/1130550

Carver, K., Joyner, K., \& Udry, J. R. (2003). National estimates of adolescent romantic relationships. In P. Florsheim (Ed.), Adolescent romantic relations and sexual behavior: Theory, research and pratical implications (pp. 23-56). NJ, US: Lawremce Erlbaum Associates Publishers.

Caspi, A., Elder, G. H., \& Bem, D. J. (1988). Moving away from the world: Life-course patterns of shy children. Developmental Psychology, 24(6), 824-831. doi: http://dx.doi.org/10.1037/0012-1649.24.6.824

Celeux, G., \& Soromenho, G. (1996). An entropy criterion for assessing the number of clusters in a mixture model. Journal of Classification, 13(2), 195-212. doi: 10.1007/BF01246098 
Cillessen, A. H., van IJzendoorn, H. W., van Lieshout, C. F., \& Hartup, W. W. (1992).

Heterogeneity among peer-rejected boys: Subtypes and stabilities. Child Development, 63(4), 893-905. doi: http://dx.doi.org/10.2307/1131241

Coie, J. D., \& Dodge, K. A. (1983). Continuities and changes in children's social status: A fiveyear longitudinal study. Merrill-Palmer Quarterly, 29(3), 261-282.

Connolly, J., Furman, W., \& Konarski, R. (2000). The role of peers in the emergence of heterosexual romantic relationships in adolescence. Child Development, 71(5), 1395-1408. doi: $10.1111 / 1467-8624.00235$

Connolly, J., Nguyen, H. N. T., Pepler, D., Craig, W., \& Jiang, D. (2013). Developmental trajectories of romantic stages and associations with problem behaviours during adolescence. Journal of Adolescence, 36(6), 1013-1024. doi: 10.1016/j.adolescence.2013.08.006

Crockett, L. J., \& Randall, B. A. (2006). Linking adolescent family and peer relationships to the quality of young adult romantic relationships: The mediating role of conflict tactics. Journal of Social and Personal Relationships, 23(5), 761-780. doi: 10.1177/0265407506068262

Cui, M., Fincham, F.D., \& Pasley, B.K. (2008). Young adult romantic relationships: The role of parents' marital problems and relationship efficacy. Personality and Social Psychology Bulletin, 34(9), 1226-1235. doi: http://dx.doi.org.proxy.bibliotheques.uqam.ca:2048/10.1177/0146167208319693

Cui, M., Ueno, K., Fincham, F. D., Donnellan, M. B., \& Wickrama, K. A. S. (2012). The association between romantic relationships and delinquency in adolescence and young adulthood. Personal Relationships, 19(2), 354-366. doi: 10.1111/j.1475-6811.2011.01366.x 
de Graaf, H., van de Schoot, R., Woertman, L., Hawk, S. T., \& Meeus, W. (2012). Family cohesion and romantic and sexual initiation: A three wave longitudinal study. Journal of Youth and Adolescence, 41(5), 583-592. doi: 10.1007/s10964-011-9708-9

Dishion, T. J., Ha, T., Véronneau, M.-H. (2012). An ecological analysis of the effects of deviant peer clustering on sexual promiscuity, problem behavior, and childbearing from early adolescence to adulthood: An enhancement of the life history framework. Developmental Psychology, 48(3), 703-717. doi: http://dx.doi.org/10.1037/a0027304

Feiring, C. (1999). Other-sex friendship networks and the development of romantic relationships in adolescence. Journal of Youth and Adolescence, 28(4), 495-512. doi: http://dx.doi.org/10.1023/A:1021621108890

Feldman, S. S., Gowen, L. K., \& Fisher, L. (1998). Family relationships and gender as predictors of romantic intimacy in young adults: A longitudinal study. Journal of Research on Adolescence, 8(2), 263-286. doi: 10.1207/s15327795jra0802_5

Fuligni, A. J., \& Eccles, J. S. (1993). Perceived parent-child relationships and early adolescents' orientation toward peers. Developmental Psychology, 29(4), 622-632. doi: http://dx.doi.org/10.1037/0012-1649.29.4.622

Furman, W. \& Shaffer, L. (2003). The role of romantic relationships in adolescent development. Dans W. Furman, B. B. Brown \& C. Feiring (dir.). The development of romantic relationships in adolescence. (1ière éd., Vol. 1., p. 3-22). Cambridge, UK : Cambridge university press.

Gazelle, H., Ladd, G. W. (2003). Anxious solitude and peer exclusion: A diathesis-stress model of internalizing trajectories in childhood. Child Development, 74(1), 257-278. doi: http://dx.doi.org/10.1111/1467-8624.00534 
Harter, S. (1988). Manual for the Self-Perception Profile for adolescents. CO, US: University of Denver.

Hill, C. T., \& Peplau, L. A. (1998). Premarital predictors of relationship outcomes: A 15-year follow-up of the Boston Couples Study. Dans T.N. Bradbury (Ed.), The developmental course of marital dysfunction. NY, US: Cambridge University Press (pp. 237-278).

Houser, J. J., Mayeux, L., \& Cross, C. (2014). Peer status and aggression as predictors of dating popularity in adolescence. Journal of Youth and Adolescence, 44(3), 683-695. doi: 10.1007/s10964-014-0174-Z

Institut de la Statistique du Québec (2012). Répartition de la population de 15 ans et plus selon la situation conjugale, le groupe d'âge et le sexe, Québec, 2011. Repéré sur le site de l’Institut de la Statistique du Québec: http://www.stat.gouv.qc.ca/statistiques/ populationdemographie/familles-menages/202_2011.htm

Institut de la Statistique du Québec (2014). Le bilan démographique, Édition 201. Repéré sur le site de l'Institut de la Statistique du Québec:

http://www.stat.gouv.qc.ca/statistiques/population-demographie/bilan2014.pdf

Kerr, M., Lambert, W. W., \& Bem, D. J. (1996). Life course sequelae of childhood shyness in Sweden: Comparison with the United States. Developmental Psychology, 32(6), 1100-1105. doi: http://dx.doi.org/10.1037/0012-1649.32.6.1100

Kreager, D. A., Molloy, L. E., Moody, J., \& Feinberg, M. E. (2015). Friends first? The peer network origins of adolescent dating. Journal of Research on Adolescence. doi: 10.1111/jora.12189 
Lanza, S. T., Collins, L. M., Lemmon, D. R., \& Schafer, J. L. (2007). PROC LCA: A SAS procedure for latent class analysis. Structural Equation Modeling, 14(4), 671-694. doi: $10.1080 / 10705510701575602$

Laursen, B., \& Collins, W. A. (2009). Parent-child relationships during adolescence. In R. M. Lerner, \& L. Steinberg (Eds.), Contextual influences on adolescent development ( $3^{\text {rd }}$ ed., vol. 2, pp. 3-42). NJ, US: John Wiley \& Sons.

Maccoby, E. E. (1998). The two sexes: Growing up apart, coming together. MA, US: Belknap Press/Harvard University Press.

Madsen, S. D., \& Collins, W. A. (2011). The salience of adolescent romantic experiences for romantic relationship qualities in young adulthood. Journal of Research on Adolescence, 21(4), 789-801. doi : http://dx.doi.org/10.1111/j.1532-7795.2011.00737.x

Martin, J. A., Hamilton, B. E., Osterman, M. J. K., Curtin, S. C., \& Mathews, T. K. (2015). Births: Final Data for 2013. National Vital Statistics Reports, 64(1). Retrieved at http://www.cdc.gov/nchs/data/nvsr/nvsr64/nvsr64_01.pdf

Masten, A. S., Morison, P., \& Pellegrini, D. S. (1985). A revised class play method of peer assessment. Developmental Psychology, 21(3), 523-533. doi: 10.1037/0012-1649.21.3.523

Metzler, C. W., Biglan, A., Ary, D. V., \& Li, F. (1998). The stability and validity of early adolescents' reports of parenting constructs. Journal of Family Psychology, 12(4), 600-619. doi: $10.1037 / 0893-3200.12 .4 .600$

Miller, S., Lansford, J. E., Costanzo, P., Malone, P. S., Golonka, M., \& Killeya-Jones, L. A. (2009). Early adolescent romantic partner status, peer standing, and problem behaviors. Journal of Early Adolescence, 29(6), 839-861. doi: http://dx.doi.org/10.1177/0272431609332665 
Newcomb, A. F., Bukowski, W. M., \& Pattee, L. (1993). Children's peer relations: A metaanalytic review of popular, rejected, neglected, controversial, and average sociometric status. Psychological Bulletin, 113(1), 99-128. doi: http://dx.doi.org/10.1037/00332909.113.1.99

Olson, D. H. (2000). Circumplex model of marital and family systems. Journal of Family Therapy, 22(2), 144-167. doi: 10.1111/1467-6427.00144

Orpinas, P., Horne, A. M., Song, X., Reeves, P. M., \& Hsieh, H. L. (2013). Dating trajectories from middle to high school: Association with academic performance and drug use. Journal of Research on Adolescence, 23(4), 772-784. doi: 10.1111/jora.12029

Perrin, P.B. Heesacker, M, Tiegs, T.J., Swan, L.K., Lawrence Jr., A.W., Smith, M.B., ... MejiaMillan, C.M. (2011). Aligning Mars and Venus: The social construction and instability of gender differences in romantic relationships. Sex Roles, 64, 613-628.

Poulin, F., \& Pedersen, S. (2007). Developmental changes in gender composition of friendship networks in adolescent girls and boys. Developmental Psychology, 43(6), 1484-1496. doi: http://dx.doi.org/10.1037/0012-1649.43.6.1484

Rauer, A. J., Pettit, G. S., Lansford, J. E., Bates, J. E., \& Dodge, K. A. (2013). Romantic relationship patterns in young adulthood and their developmental antecedents. Developmental Psychology, 49(11), 2159-2171. doi: 10.1037/a0031845

Rubin, K. H., Bukowski, W. M., \& Parker, J.G. (2006). Peer interactions, relationships, and groups. In W. Damon, \& R. M. Lerner (Eds.), Handbook of child psychology ( $6^{\text {th }}$ ed., vol. 3, pp. 571-645). NJ, US: John Wiley \& Sons.

Rubin, K. H., \& Coplan, R. J. (2010). The development of shyness and social withdrawal. NY, US: Guilford Press. 
Rubin, K. H., Wojslawowicz, J. C., Rose-Krasnor, L., Booth-LaForce, C., \& Burgess, K. B. (2006). The best friendships of shy/withdrawn children: Prevalence, stability, and relationship quality. Journal of Abnormal Child Psychology, 34(2), 143-157. doi: http://dx.doi.org/10.1007/s10802-005-9017-4

Seiffge-Krenke, I. (2000). Diversity in romantic relations of adolescents with varying health status: Links to intimacy in close friendships. Journal of Adolescent Research, 15(6), 611636. doi : http://dx.doi.org/10.1177/0743558400156001

Seiffge-Krenke, I. (2003). Testing theories of romantic development from adolescence to young adulthood: Evidence of a developmental sequence. International Journal of Behavioral Development, 27(6), 519-531. doi: 10.1080/01650250344000145

Shulman, S., \& Connolly, J. (2013). The challenge of romantic relationships in emerging adulthood: Reconceptualization of the field. Emerging Adulthood, 1(27), 27-39. doi: $10.1177 / 2167696812467330$

Shulman, S., Scharf, M., Livne, Y., \& Barr, T. (2013). Patterns of romantic involvement among emerging adults: Psychosocial correlates and precursors. International Journal of Behavioral Development, 37(5), 460-467. doi: 10.1177/0165025413491371.

Shulman, S., Tuval-Mashiach, R., Levran, E., \& Anbar, S. (2006). Conflict resolution patterns and longevity of adolescent romantic couples: A 2-year follow-up study. Journal of Adolescence, 29(4), 575-588. http://dx.doi.org/10.1016/j.adolescence.2005.08.018

Steinberg, L. (2001). We know some things: Parent-adolescent relationships in retrospect and prospect. Journal of Research on Adolescence, 11(1), 1-19.

doi: http://dx.doi.org/10.1111/1532-7795.00001

Sullivan, H. S. (1953). The interpersonal theory of psychiatry. New York: W. W. Norton \& Co. 
United States Census Bureau. (2012). Estimated median age at first marriage, by sex: 1890 to the present. Retrieved on United States Census Bureau's website: http://www.census.gov/population/socdemo/hh-fam/ms2.xls

Zimmer-Gembeck, M. J., Siebenbruner, J., \& Collins, W. A. (2001). Diverse aspects of dating: Associations with psychosocial functioning from early to middle adolescence. Journal of Adolescence, 24(3), 313-336. doi: 10.1006/jado.2001.0410

Zimmer-Gembeck, M.J., \& Collins, A. (2008). Gender, mature appearance, alcohol use, and dating as correlates of sexual partner accumulation from ages 16-26 years. Journal of Adolescent Health, 42(6), 564-572. doi: http://dx.doi.org/10.1016/j.jadohealth.2007.11.004 


\section{Tables}

Table 1

Fit Statistics for Latent Class Analysis

\begin{tabular}{lccccc}
\hline Number of classes & LL & AIC & BIC & SSA-BIC & Entropy \\
\hline 2 & -1229.79 & 2473.58 & 2499.05 & 2476.85 & .91 \\
3 & -1190.77 & 2401.53 & 2437.91 & 2406.20 & .89 \\
4 & -1177.23 & 2380.46 & 2427.76 & 2386.54 & .83 \\
$\mathbf{5}$ & $\mathbf{- 1 1 6 1 . 1 7}$ & $\mathbf{2 3 5 4 . 3 3}$ & $\mathbf{2 4 1 2 . 5 5}$ & $\mathbf{2 3 6 1 . 8 1}$ & $\mathbf{. 8 0}$ \\
6 & -1158.67 & 2355.35 & 2424.47 & 2364.23 & .78 \\
\hline
\end{tabular}

Note. Boldface type indicates the selected model; $\mathrm{LL}=$ Log-Likelihood; AIC $=$ Aikaike

Information Criterion; BIC = Bayesian Information Criterion; SSA-BIC $=$ sample-size adjusted BIC. 
Table 2

Identification of Romantic Relationship Patterns

\begin{tabular}{lccccc}
\hline & \multicolumn{5}{c}{ Romantic relationship patterns } \\
\cline { 2 - 6 } Variables & $\begin{array}{c}\text { Later } \\
(n=33)\end{array}$ & $\begin{array}{c}\text { Sporadic } \\
(n=59)\end{array}$ & $\begin{array}{c}\text { Long-term } \\
(n=136)\end{array}$ & $\begin{array}{c}\text { Frequent } \\
(n=41)\end{array}$ & $\begin{array}{c}\text { Intense } \\
(n=12)\end{array}$ \\
\hline Latent class analysis & & & & & \\
Number of partners & $1.30(0.95)_{\mathrm{a}}$ & $2.90(1.54)_{\mathrm{b}}$ & $3.21(1.30)_{\mathrm{b}}$ & $7.08(0.96)_{\mathrm{c}}$ & $11.58(1.56)_{\mathrm{d}}$ \\
Number of years in a RR & $1.88(1.05)_{\mathrm{a}}$ & $5.31(0.77)_{\mathrm{b}}$ & $8.17(0.81)_{\mathrm{c}}$ & $8.29(0.84)_{\mathrm{c}}$ & $8.42(0.67)_{\mathrm{c}}$ \\
\hline
\end{tabular}

Note. Means with different subscripts within a row are significantly different from one another $(p<.05)$. 
Table 3

Descriptives Statistics for External and Demographic Variables for each Romantic Relationship Pattern

\begin{tabular}{|c|c|c|c|c|c|}
\hline \multirow[b]{2}{*}{ Variables } & \multicolumn{5}{|c|}{ Romantic relationship patterns } \\
\hline & Later & Sporadic & Long-term & Frequent & Intense \\
\hline \multicolumn{6}{|l|}{ External } \\
\hline Longest relationship & $1.27(0.91) \mathrm{a}$ & $3.05(1.20)_{b}$ & $5.24(1.65)_{\mathrm{c}}$ & $3.83(1.26)_{b}$ & $3.25(1.06)_{b}$ \\
\hline Age at first relationship & $19.88(3.54)_{\mathrm{a}}$ & $16.98(1.38)_{b}$ & $16.33(0.66)_{b}$ & $16.17(0.44)_{b}$ & $16.00(0.00)_{b}$ \\
\hline \multicolumn{6}{|l|}{ Demographic } \\
\hline Gender (\% girls) & 36.36 & 44.07 & 69.85 & 70.73 & 91.67 \\
\hline Family structure (\% intact) & 81.81 & 75.86 & 74.81 & 73.17 & 100.00 \\
\hline
\end{tabular}

Note. Means with different subscripts within a row are significantly different from one another $(p<.05)$. 
Table 4

Means (and Standard Deviations) of Family and Peer Experiences for each Romantic Relationship Pattern

\begin{tabular}{lcccccc}
\hline & \multicolumn{5}{c}{ Romantic relationship patterns } \\
\cline { 2 - 6 } Variables & Later & Sporadic & Long-term & Frequent & Intense & F (4, 276) \\
\hline Family cohesion & $3.71(0.98)$ & $4.01(0.81)$ & $3.93(0.88)$ & $3.97(0.76)$ & $3.57(0.87)$ & 1.10 \\
Parent-child conflict & $1.46(0.53)_{\mathrm{a}}$ & $1.63(0.74)_{\mathrm{a}}$ & $1.79(0.79)_{\mathrm{a}}$ & $1.78(0.87)_{\mathrm{a}}$ & $2.56(1.47)_{\mathrm{b}}$ & $5.99^{* *}$ \\
Peer likeability & $-0.72(1.73)_{\mathrm{a}}$ & $0.00(1.34)_{\mathrm{a}, \mathrm{b}}$ & $0.39(1.47)_{\mathrm{b}}$ & $0.11(1.55)_{\mathrm{a}, \mathrm{b}}$ & $0.77(1.12)_{\mathrm{b}}$ & $4.52^{* *}$ \\
Social withdrawal & $0.50(1.40)_{\mathrm{a}}$ & $-0.07(0.70)_{\mathrm{a}, \mathrm{b}}$ & $-0.11(0.80)_{\mathrm{b}}$ & $-0.25(0.44)_{\mathrm{b}}$ & $-0.17(0.55)_{\mathrm{b}}$ & $4.41^{* *}$ \\
Close friendships & $3.03(0.64)_{\mathrm{a}}$ & $3.12(0.69)_{\mathrm{a}, \mathrm{b}}$ & $3.38(0.62)_{\mathrm{a}, \mathrm{b}}$ & $3.50(0.51)_{\mathrm{b}}$ & $3.35(0.67)_{\mathrm{a}, \mathrm{b}}$ & $4.43^{* *}$ \\
Other-sex friendships & $0.09(0.16)_{\mathrm{a}}$ & $0.15(0.14)_{\mathrm{a}, \mathrm{b}}$ & $0.15(0.16)_{\mathrm{a}, \mathrm{b}}$ & $0.21(0.18)_{\mathrm{b}}$ & $0.24(0.20)_{\mathrm{b}}$ & $3.36^{* *}$ \\
\hline
\end{tabular}

Note. Means with different subscripts within a row are significantly different

from one another $(p \leq .05)$.

$* * \mathrm{p}<.05$ 